\title{
Implementation of a British computer system for laboratory data handling
}

\author{
C. H. GRAY, A. D. HIRST, P. J. N. HOWORTH, T. P. LOCKE, B. MELLOR ${ }^{1}$, \\ AND M. WALTER
}

From the Department of Chemical Pathology, King's College Hospital, Denmark Hill, London

SYNOPSIS This paper describes the development and implementation of a small real-time British computer system for the handling of patient and test result data in the chemical pathology laboratories of the King's Health District (Teaching). Work destined for subsequent reporting by the computer system is entered by continuous on-line teletype. Test result data from multichannel analyzers are input using an on-line trace reader. Cumulative reports are printed both by line printer at the central laboratory and by on-line teletypes at two peripheral hospital laboratories. In a working day over 4000 new items of data are generated and 300-500 reports printed. The use of a trace reader as an inputing device and the method of employing a high capacity disk to give both speed of operation and limited archive facility are discussed.

This paper describes early experience with the implementation of a Digico Micro 16P computer system for data handling in the Department of Chemical Pathology, King's College Hospital Group. A preliminary account has been published elsewhere (Gray and Walter, 1971). The equipment now consists of a 12K Micro 16P computer, CDC 9421 dual disk drive, Normalair-Garrett trace reader, ICL 667 line printer $(550 \mathrm{lpm})$, and six on-line teletypes, two of which are sited at St Giles Hospital and Dulwich Hospital, each about 1.5 miles from the laboratory. The system accepts patient data via teletype, creates and prints worksheets, accepts results from an on-line trace reader, and creates and prints cumulative reports.

\section{Description}

THE LABORATORY REQUIREMENTS

The installation of a computer system was necessitated by the large increase in work which took place in the late 1960 s after the introduction of the AutoAnalyzer ${ }^{2}$ as a routine laboratory tool. The following indicates basic requirements for a comprehensive laboratory computer system:

1 The system should keep account of all laboratory

Received for publication 5 September 1974.

1 Of Digico Ltd.

'Technicon Instruments Co. Ltd. transactions and alert staff when results are delayed or overlooked. Successive reports for any one patient should be presented on a single form.

2 Ease of access to the computer system by ordinary laboratory personnel is mandatory.

3 Speed of response is essential since the system must produce feedback within the laboratory to aid the control of both manual and automatic methodology.

4 The system must facilitate data evaluation, eg, quality control.

5 Computer systems should not produce excessive amounts of marginally useful data.

THE EQUIPMENT

The Micro 16P computer was installed in January 1972 and replaced a Micro $16 \mathrm{~S}$. The computer does not have an executive or operating system which would simplify real-time programming. The initial system had only $8 \mathrm{~K}$ of core memory to which $4 \mathrm{~K}$ was added to meet later developments.

The CDC 9421 dual disk drive unit can hold about 8000 different patients' records at any one time. The mean average access time $(160 \mathrm{msec})$ has become a rate-limiting factor. Due to the heavy mechanical work required of it, this unit has required the most maintenance.

The Normalair-Garrett trace reader consists of a metal baseplate $(40 \mathrm{~cm} \times 35 \mathrm{~cm})$ across which is applied a potential difference of 1 volt. Electrical 
contact must be made through the chart paper with the baseplate using a metal probe. The device contains a digital voltmeter and the ' $Y$ ' position of the probe is displayed digitally on the instrument. It is necessary to observe the digital readout during each probing operation to check its validity since a warning light intended to indicate inadequate contact with the baseplate has been unsatisfactory. Being a ' $Y$ ' plotter only, it is impracticable to guard against double probing or misprobing by program control.

Four ASR 33 teletypes are used; the console teletype is linked to the CPU via the slow interface and three more are linked via the multiplexer. One of these three is in the central laboratory and is used for data input, the others are in Dulwich and St Giles hospitals, linked via two pairs of private telegraph lines. Two teletypes are held as a back-up facility and to cater for possible expansion of the system. There are no modems or repeaters in the circuit which is duplex and has a data transmission rate of 110 bauds. The remote teletypes, being on-line, function as do the locally sited multiplexed teletype.

\section{SOFTWARE CONSTRUCTION}

The disk is used both as a backing store and as an input/output (I/O) storage and retrieval device, using the outer tracks numbered $0-5$. Next to these tracks are the various indices, which are accessed more frequently than individual patient records. Patient records and program overlays occupy the remainder of the disk.

\section{Spooling}

All other peripherals have their input/output held on the disk. This stores up to 2400 words or $\mathbf{4 8 0 0}$ characters of input/output data until the computer is free to deal with them; thus input data need not be analysed immediately. At an average of four characters per second input from a teletype, a competent operator could type for 20 minutes before the spooling track is full.

Delays of more than a few seconds are rare and occur only when the job queue is long and complex. Spooling enables all peripherals to be operated on different jobs simultaneously. Trace reader input, real-time printout, patient data input, worksheet/ daybook listings, and report printing at local and both remote terminals frequently occur simultaneously. The volume of work and the slowness and limitation of character printers has necessitated a fast line printer.

\section{Job queuing}

The program allocates a priority to jobs in a list, which can be any length. After a processing job is complete the scanning starts at the high priority end of the queue and not after the last executed job. Inputs have a higher priority than outputs, with patient data input having the highest priority of all. Automatic report printing, except when required urgently, has a relatively low priority. Several jobs, eg, call for worksheets, daybook, manually requested reports, may be set by the operator; the system will then work through automatically deleting the job required' flag at the completion of each one.

\section{Program overlays}

The system programs are some 14000 words in length and were written in Micro 16 assembler. Since the core size was originally limited to $8 \mathrm{~K}$ about half the program is held on disk as a series of overlays (table I). These parts of the program contain the applications packages and it is therefore relatively simple to adapt the system to meet new conditions. When a job is required the appropriate overlay is read into core. At intervals, an overlay transferred in core may be written back to disk, allowing one or more other overlays in core to time share the CPU. Since all the input/output routines are obviously

\begin{tabular}{|c|c|}
\hline Function & Program Description \\
\hline $\begin{array}{l}\text { Report generator } \\
\text { SMA } 12 / 60 \text { program } \\
\text { SMA } 6 / 60 \text { program } \\
\text { Patient input } \\
\text { Change commands } \\
\text { Get commands } \\
\text { Date/time printout } \\
\text { MRES } \\
\text { RES } \\
\text { TIDY and statistics } \\
\text { Worksheet/daybook } \\
\text { Urine profile }\end{array}$ & $\begin{array}{l}\text { Produces cumulative reports and prints them at both the central and peripheral hospitals } \\
\text { Takes digital values from trace reader, recalculates result values, places them in patients' } \\
\text { files } \\
\text { Permits new entries to the patient files } \\
\text { Allows any item of data in the system to be changed } \\
\text { Allows interrogation of the system } \\
\text { Prints out date and time on request } \\
\text { Input of result data using worksheet index } \\
\text { Input of result data using unit no./lab. no. } \\
\text { Housekeeping procedures } \\
\text { Prints out automatically these lists } \\
\text { Interprets AAl peaks via trace reader, calculates results } / 24 \mathrm{hr} \text {, places results in patients' files }\end{array}$ \\
\hline
\end{tabular}

Table I Some of the functions held as command processing programs (system overlays) 
resident in core, this time sharing is fast and has proved to be very reliable. Reloading a corrupted overlay from paper tape is a rare but simple operation.

\section{Mode of Operation}

\section{STAFFING THE SYSTEM}

Patient data inputing is shared between two typists; other staff perform this function in an emergency. All experienced technicians and biochemists receive training for two weeks before operating the trace reader as part of the general rotation of staff duties.

\section{PATIENT INPUT}

Patients' details are placed ON FILE by the patient input $(\mathrm{P} / \mathrm{I})$ program. Patient input may be used simultaneously at all terminals. The patient's unit number, which is the sole field by which a record is identified, is entered, preceded by a double asterisk which initiates patient input. The program responds by typing the first laboratory number in the string. Patient input awaits a response of either ' $Y$ ' accept or ' $N$ ' reject for this number.

If, because a mistake has been made, the operator types ' $N$ ' $P / I$ is aborted. If ' $Y$ ' then the program will either respond with the code NOF (not on file) in which case the operator must type in the name, ward, consultant code, date of birth, sex, and clinical details of the patient, followed by the test codes, or, if the patient's details are already in the system, the name, ward, consultant, and clinical details fields will be automatically typed out. The operator visually checks that these are correct and types the test codes for the required investigations. The system responds with an ' $O K$ ', and terminates this program. If necessary any field of the report, eg, ward name, may be changed subsequently. Errors in other data fields can easily be corrected at the termination of each input and at any other time. If, after the acceptance of a laboratory number, the name of the patient on file is incorrect the entry may be aborted.

Patient input creates an entry in the patient file index, allocates file space (one half sector) setting a flag in the file space index, creates entries on the appropriate worksheet and daybook indexes, increases the work summary file by one for the appropriate chemistries, and sets the patient stay count to zero.

\section{ERRORS ON INPUT}

The most serious error has been the misquotation or the illegible quotation by the requesting clinician of the patient's unit no. (between $3-5 \%$ of all records). This occurs when the King's College Hospital Group mechanical registration system is not used. Unit numbers may be changed in the system but it is impossible to unite patient files which have been entered under two different unit numbers. For reasons of speed and space $P / I$ does not associate name and number. Mistyping of this number by our operator is surprisingly rare and so cumulative reports are obtained so long as the clinician takes care to quote the correct, or at least the same unit number on each request.

\section{PATIENT'S STAY COUNT (USE OF THE TIDY COMMAND)}

The stay count is used to control the length of time a record is retained in the system. Each day stay counts of all patient's files are increased by one by the housekeeping routine TIDY. When a stay count reaches a predetermined number, which may be preset by keyboard command, a copy of the entire cumulative record is printed bearing the label 'LAB COPY'. At the next TIDY command all such records are deleted and file space flags unset. Our system stay count has been set to 21 days but since the computer does not operate at weekends, records remain on file for up to some $\mathbf{3 0}$ days after the last request. ${ }^{1}$ Since no special attempt is made to provide cumulative reports for outpatients this stay count is adequate.

The STAY count may be returned to zero at any time by keyboard command if a record needs to be retained in the system. On average, 300 requests are received per day with a test-request ratio of $10: 1$ (due to multichannel analyzers). With the file at equilibrium with about $40 \%$ of incoming patients ON FILE, a typist can enter patient's details at a rate of $2 \cdot 5$ requests per minute.

\section{Worksheets}

Worksheets are produced automatically when 40 entries (the number of positions on an AutoAnalyzer plate) have accumulated; the format informs the technical staff of the precise plate-loading sequence.

The format of a worksheet, ie, the position of drifts and standards, can be changed by keyboard command.

A worksheet, or partial worksheet, may be requested at any time and is printed with high priority. The index is held on the disk as a circular list nine worksheets in length. The tenth worksheet overwrites the first. This saves valuable disk space and, although a limitation, also ensures that the laboratory analyzers can never be allowed to fall too far behind the current input.

${ }^{1}$ About $60 \%$ files have one request only and it is rare for second requests to be made after 16 days. 


\begin{tabular}{|c|c|c|c|c|c|c|}
\hline $12 \cdot 8 \cdot 74$ & $12 \cdot 30$ & DAY & YBOUK & & $A G E$ & 38 \\
\hline HOSP-ND & CDNS & W ARD & TIME/R & $L A B-N O$ & TES & \\
\hline $\begin{array}{l}0506046 \\
0514349\end{array}$ & $\begin{array}{l}\text { JA } \\
\text { CGM }\end{array}$ & $\begin{array}{l}A C W K \\
T+W K\end{array}$ & $\begin{array}{l}11 \cdot 17 \\
11 \cdot 17\end{array}$ & $\begin{array}{l}50643 \\
50644\end{array}$ & $\begin{array}{l}E L \\
E L\end{array}$ & $\begin{array}{l}\text { SMA } \\
\text { SMA }\end{array}$ \\
\hline 0180464 & CGMK & $T+W K$ & $11 \cdot 17$ & 50645 & EL & \\
\hline 0763793 & $F D-K$ & $A Z-K$ & $11 \cdot 18$ & 50646 & EL & SMA \\
\hline 0730205 & SO & $A Z-K$ & $11 \cdot 19$ & 50647 & EL & SMA \\
\hline 0764195 & $\mathrm{HR}$ & F ERK & $11 \cdot 19$ & 50648 & EL & \\
\hline 0655344 & $\cdots$ & $T+W K$ & $11 \cdot 20$ & 50649 & SMA & \\
\hline 0192428 & C TH & $P R-K$ & $11 \cdot 20$ & 50650 & EL & SMA \\
\hline 0145338 & $\mathrm{MCK}$ & $T+W K$ & $11 \cdot 21$ & 50651 & SMA & \\
\hline 0542302 & CTH & $P R-K$ & $11 \cdot 21$ & 50652 & EL & SMA \\
\hline 0795165 & CGM & $T+W K$ & $11 \cdot 22$ & 50653 & SMA & \\
\hline 0763768 & $R w^{-}$ & T ODK & $11 \cdot 22$ & 50654 & SMA & \\
\hline 0767165 & CGM & TRUK & $11 \cdot 22$ & 50655 & SMA & \\
\hline 0794965 & ---- & STOK & $11 \cdot 23$ & 50658 & EL & SMA \\
\hline 0653762 & SO & STOK & $11 \cdot 24$ & 50661 & EL & SMA \\
\hline 0425221 & $-\cdots$ & STOK & $11 \cdot 24$ & 50662 & EL & SMA \\
\hline 0763777 & PYKE & R DLK & 11.47 & 50232 & UPR & \\
\hline 0646128 & RW & $A 7-K$ & 11.47 & 50233 & UPR & \\
\hline 0629572 & F IRM & $A Z-K$ & $11 \cdot 48$ & 50234 & UPR & $\mathrm{CCRT}$ \\
\hline 0546055 & $\cdots$ & G ERG & $11 \cdot 48$ & 50235 & UPR & CCRT \\
\hline 0423641 & V P & SOPK & 11.49 & 50236 & UPK & CCRI \\
\hline X0 50237 & - & PP3K & $11 \cdot 49$ & 50237 & UPR & \\
\hline 0543732 & VP & SOPK & $11 \cdot 50$ & 50238 & UPR & \\
\hline 0508585 & CMK & $O P-G$ & $11 \cdot 50$ & 50239 & UPR & \\
\hline 0655344 & $\cdots-$ & $T+W K$ & $11 \cdot 50$ & 50240 & UPR & \\
\hline 0145338 & MCK & $T+W K$ & 11.51 & 50241 & UPR & \\
\hline 0341639 & $\mathrm{PHF}$ & ALLD & $11 \cdot 51$ & 50242 & UPR & \\
\hline 0515235 & VP & MOPD & $11 \cdot 51$ & 50243 & UPR & \\
\hline 0355378 & UP & $R U-D$ & $11 \cdot 52$ & 50244 & UPR & \\
\hline 0180715 & $\mathrm{EBDH}$ & CHAG & $11 \cdot 52$ & 50245 & UPR & \\
\hline 0145338 & $\mathrm{MCK}$ & $T+w K$ & $11 \cdot 53$ & 50246 & UPR & \\
\hline 0655344 & --- & $T+W K$ & $11 \cdot 54$ & 50247 & UPR & \\
\hline$\times 1050248$ & DI & CPLK & $11 \cdot 55$ & 50248 & UPR & \\
\hline 0795165 & CGM & $T+w K$ & $11 \cdot 55$ & 50249 & UPR & \\
\hline 0639178 & $-\cdots$ & T ODK & $11 \cdot 55$ & 50250 & UPR & \\
\hline 0639631 & VP & RUSD & $11 \cdot 56$ & 50251 & UPK & \\
\hline 0099942 & UP & G OLD & $11 \cdot 57$ & 50252 & UPR & \\
\hline 0505711 & $P J W$ & $D 2-D$ & 11.57 & 50253 & UPR & \\
\hline 0732261 & $V P$ & $C 2-D$ & $11 \cdot 59$ & 50254 & UPR & \\
\hline 0204213 & $V P$ & CHAD & $12 \cdot 0$ & 50255 & UPK & \\
\hline
\end{tabular}

Fig 1 A daybook page (the right hand column of patients' names has been omitted).
DAYBOOK FILE

This is a chronological list of inputs (fig 1), having 40 entries to the page. Work arrears is a listing of the incomplete records in the last nine daybook pages.

\section{WORK SUMMARY}

This gives cumulative totals for each test until the totals are reduced to zero by keyboard command monthly. Statistics at present consist of a mean and standard deviation for each series of automated analyses and can be performed at any time. Quality control sera are not specially treated by the com- puter and the significance of the results obtained is, at present, assessed independently of the computer.

INPUT OF RESULTS

Test results may be entered in three ways. (1) Via trace reader, when signals from the trace reader are ignored by the system until a probe command has been given. After this the sequence of probes is crucial and care must be taken to ensure the validity of each probe. (2) Via keyboard, using the worksheet to find the patients' records (MRES), and (3) via keyboard, searching on unit no. and then laboratory 
no. This is necessary when the worksheet index is no longer available (RES).

\section{Trace Reader}

\section{AA 1 CHARTS (URINE PROFILE)}

The calibration peaks are probed in ascending order of concentration followed by the test and drift standard peaks. The calibration values are held in the program and may be changed by keyboard command in real time mode. The calibration curve consists of linear interpolation between adjacent peaks; no attempt at 'curve fitting' has yet been made. At present curve validation by visual inspection is preferable rather than by software.

Drift correction is an integral part of the program. An experiment was performed to estimate the effect of using the trace reader to calculate results compared with the standard manual method using AutoAnalyzer I charts. Two technicians independently analysed 50 random sera for sodium, potassium, and urea using AutoAnalyzer I equipment and calculated the results from the charts by (1) the standard manual procedure and (2) using the trace reader. The results, summarized in table II, show clearly that on channels where drifting is significant, eg, $\mathrm{Na}^{+}$and $\mathrm{K}^{+}$, the use of the trace reader provides a more accurate means of peak probing than does the usual manual method. Human skill is still required to probe each peak correctly; such an inherent error would be removed if the analyzers were on-line. A six-channel urine profile (AA1) plate (40 cups providing 240 peaks) can be probed in about eight minutes, a $6 / 60$ plate in six min, and a $12 / 60$ plate in 12 minutes.
S M A CHARTS

In addition to probing the analytical plateaux, each chart is first probed at the left hand baseline, the left hand top of scale, and on the right hand baseline. This sets the calibration parameters for the chart and enables the program to correct for any skewness of the chart on the trace reader.

Our daily average throughput is five plates of SMA $12 / 60$ analyses and four to five plates of SMA $6 / 60$ analyses per day, requiring in all between 4000 and 5000 probes. Although this method of data capture is superior to visual reading, trained technicians could be better employed and we would not recommend the use of this technique to tackle such a large volume of work.

Manual peak validation means a great saving in terms of core memory and programming effort and retains the flexibility of manual techniques. When a plate has been probed, the 'job' is terminated by the operator giving a negative value by probing below the baseline on the trace reader. Throughout probing there is a 'real-time printout' (RTIM) of the final results on the console teletype, which both enables the operator to check for errors and is kept as the permanent laboratory record of results produced by the analyzers (see above).

Amendments to the values on the RTIM, ie, dilutions, corrections, deletions, are typed in using the MRES function.

\section{Production of Reports}

These are cumulative; after amendments to results have been made and a specified accept command (ACPT) is given, the entire worksheet of reports is

\begin{tabular}{|c|c|c|c|c|c|c|}
\hline & \multicolumn{3}{|c|}{ Observer 1 Manual Reading of Results } & \multicolumn{3}{|c|}{ Observer 2 Trace Reader Results } \\
\hline & $M e a n \pm S D$ & $\begin{array}{l}S D \text { of } \\
\text { Difference } \\
\text { between Pairs } \\
\text { of Readings }\end{array}$ & $\begin{array}{l}\text { Significance } \\
\text { of Paired } t \\
\text { Tests }\end{array}$ & Mean $\doteq S D$ & $\begin{array}{l}\text { SD of } \\
\text { Difference } \\
\text { between Pairs } \\
\text { of Readings }\end{array}$ & $\begin{array}{l}\text { Significance } \\
\text { of Paired } t \\
\text { Tests }\end{array}$ \\
\hline $\begin{array}{l}\text { Channels affected } \\
\text { (a) } \mathrm{Na}^{+} \mathrm{mmol} / 1 \\
\text { Observer } 1 \\
\text { Observer } 2\end{array}$ & $\begin{array}{ll}137 \cdot 1 & 4.99 \\
137.6 & 4.63\end{array}$ & 0.64 & $P<0.001$ & $\begin{array}{ll}138 \cdot 2 & 4 \cdot 87 \\
138 \cdot 1 & 4 \cdot 88\end{array}$ & $0 \cdot 35$ & NS at $5 \%$ \\
\hline $\begin{array}{l}\text { (b) } \mathrm{K}^{+} \text {mmol/1 } \\
\text { Observer } 1 \\
\text { Observer } 2\end{array}$ & $\begin{array}{ll}4 \cdot 17 & 0 \cdot 76 \\
4 \cdot 11 & 0 \cdot 76\end{array}$ & 0.050 & $P<0.001$ & $\begin{array}{ll}4.15 & 0.76 \\
4.14 & 0.74\end{array}$ & 0.033 & NS at $5 \%$ \\
\hline $\begin{array}{c}\text { Channel not affecte } \\
\text { Urea }(\mathrm{mg} / \mathrm{dl}) \\
\text { Observer } 1 \\
\text { Observer } 2\end{array}$ & $\begin{array}{ll}54.9 & 47.4 \\
55.2 & 48.4\end{array}$ & 1.04 & NS at $5 \%$ & $\begin{array}{ll}55.5 & 48.4 \\
55.3 & 48.4\end{array}$ & 0.80 & NS at $5 \%$ \\
\hline
\end{tabular}

Table II Precision of results ${ }^{1}$ from AutoAnalyzer I charts determined by two separate observers (1) with manual standard curves and (2) using the NGL trace reader

${ }^{1}$ Mean and standard deviation are calculated from an untruncated series of $\mathbf{5 0}$ measurements. 
printed with earlier reports, irrespective of completion, results not yet available being designated TF (to follow).

The report format is teletype orientated with the individual chemistries arranged in rows. The latest request always occupies the left hand column and displaces its predecessor to the right (fig 2).

The latest computer-produced report for a patient displaces the previous one in the clinical note folder since it will contain all the laboratory data for that patient up to the last eight requests and the old report should be discarded. When generating a report carrying a 'unique' set of eight report blocks the report form is labelled 'do not discard' but there is a tendency for ward staff to retain all reports.

Reports for Dulwich and St Giles Hospitals are printed on their respective teletypes together with

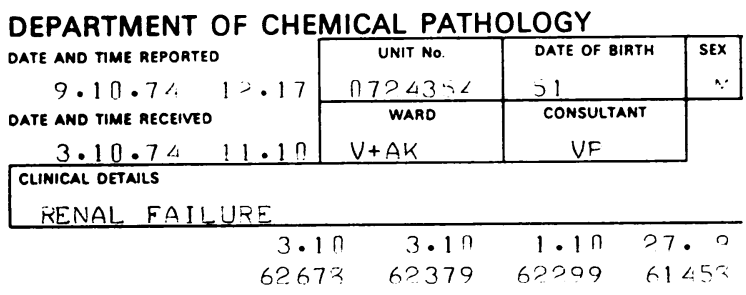

\begin{tabular}{|c|c|c|c|}
\hline \multicolumn{4}{|c|}{ ELECTRRLYTES } \\
\hline \multicolumn{3}{|c|}{ SกDI UM } & 1.36 \\
\hline \multicolumn{3}{|l|}{ PRTASSI U } & $3 \cdot 5$ \\
\hline \multicolumn{3}{|l|}{ BI CARP. } & $1 ?$ \\
\hline \multicolumn{3}{|l|}{ UREA } & $39 ?$ \\
\hline \multicolumn{3}{|l|}{ CREAT I NI $:$} & 41 \\
\hline \multicolumn{3}{|l|}{ ALUCASE } & $15 \%$ \\
\hline \multicolumn{4}{|l|}{ SMA $1 ?$} \\
\hline \multicolumn{3}{|l|}{ CALCIUIM } & $6 \cdot 1$ \\
\hline \multicolumn{3}{|l|}{ PHISPHAT: } & $9 \cdot 1$ \\
\hline \multicolumn{3}{|l|}{$* * * * * * *$} & $N A$ \\
\hline \multicolumn{3}{|l|}{ UREA } & 41 \\
\hline \multicolumn{3}{|l|}{ URIC ACI: } & 9.9 \\
\hline \multicolumn{3}{|l|}{$* * * * * * *$} & $N \cdot A$ \\
\hline \multicolumn{3}{|l|}{ PRCTEIN } & 5.0 \\
\hline \multicolumn{3}{|l|}{ ALRUMIN } & $3 \cdot 3$ \\
\hline \multicolumn{3}{|l|}{ BILI SUPI } & $n \cdot 5$ \\
\hline \multicolumn{3}{|l|}{ ALK.PHTIS. } & 96 \\
\hline \multicolumn{3}{|l|}{ H.B.D. } & 107 \\
\hline \multicolumn{4}{|c|}{$A \cdot S \cdot T \cdot$} \\
\hline \multicolumn{4}{|c|}{ URINE rririLE } \\
\hline VTLUNE & 0.24 & $? .5 \%$ & \\
\hline STUIUN & 41 & 120 & \\
\hline PTTASSI U & 19 & $6 \pi$ & \\
\hline CALCIUN & $2 n$ & $1 \cap n$ & \\
\hline PHTISPHAT: & 1.19 & 0.41 & \\
\hline UREA & $3 \cdot 3$ & 20.5 & \\
\hline CFEATINI E & 0.47 & $1 \cdot 15$ & \\
\hline CALC ICREAT & $\cap . ก 4$ & 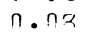 & \\
\hline
\end{tabular}

Fig $2 A$ cumulative report. The right hand box containing the patient's name has been omitted. 7.3

$7 \cdot{ }^{2}$ 139 6h copies printed simultaneously at King's College Hospital to permit inspection of the report by the pathologist. Printed reports which need further investigation are delayed by a telephone call to the remote terminal. Error rate in transmission is said by the manufacturers to be less than one in 10000 characters but so far we have failed to detect any errors apart from faults on the teletype. Tape copies of the previous day's transmissions are checked periodically. The success of this aspect of the system is due to the private telegraph lines, the slow data transmission rate with avoidance of modems, and an on-line mode for the remote terminals which obviates the need to use teletype tape readers.

\section{ERROR MESSAGES}

The system employs two kinds of error messages. First, there are messages which inform the operator of keyboard and data errors such as 'wrong unit no'. and incorrect commands. Secondly, an error may arise such as a wrongly addressed disk track or an instruction which causes the disk to seek a nonexistent track. These faults are rare and may be due to hardware or software.

\section{Modifications to the Original System}

The most serious modification necessary has been the reduction in the variety of tests handled by the computer. The computer now handles SMA $12 / 60$ and 6/60 analyses, urine profile (Hirst and Howorth, 1974), electrophoresis quantitation, enzyme profile, thyroid function, and creatinine clearance results. Experience quickly showed the need for additional terminals as well as staff if all results of manual tests 7.4 were to be input by teletype. All other work (about $4.210 \%$ of our throughput) is not introduced into the V: computer system and is dealt with by other methods.

\section{V: Clinical Acceptance}

$4 . \rightarrow$ Changes in laboratory techniques which have en-

0.5 couraged the use of electronic data handling equip$1.3 \%$ ment are the development of systems for multiple analysis and the recognition of the usefulness of cumulative reports to both the clinician at the bedside and the clinical chemist in the laboratory. The doctor can rapidly assess sequential changes and the clinical chemist finds it easier to detect gross errors in the laboratory.

\section{Downtime}

'Downtime' in this system means any weekday time between 09.00 and $17.30 \mathrm{hr}$ when the system is not running. Run time includes all the time the system is 
running including times at weekends and in the evening.

In 1973 our routine maintenance was performed outside laboratory hours and table III illustrates the magnitude of the disk problem in relation to other faults. The disk, on which all the early development work was performed, developed a worn bearing on the access assembly at about 4000 hours of running time.

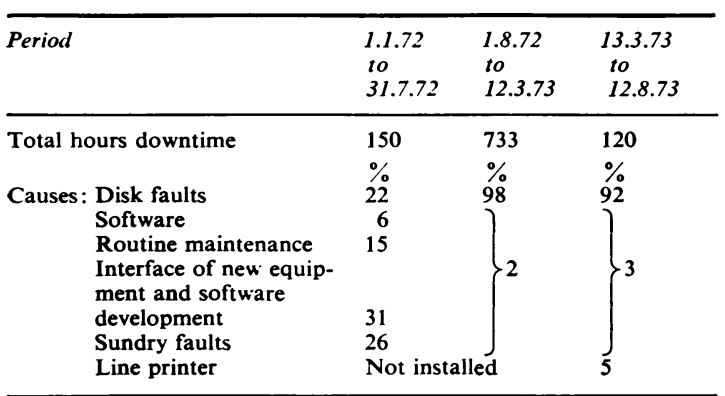

Table III Downtime

Table III also shows the proportion of downtime for the six months from 12 March 1973. During this period the system began handling additional work from the urine analyzer and electrophoresis, enzyme profile, and thyroid function results. Disk downtime was again due to a second worn bearing surface. The trace reader has proved very reliable and the micro 16P CPU has so far not failed. The original teletypes are all still in use. The two RO33 teleprinters have both logged about 3000 hours each. A teletype failure does not stop the system as its function can be given to another machine either by keyboard command or by plugging in a spare teletype.

Mean time between failures is often taken as a measure of reliability, although 'failures' differ widely in importance. We experience two or three illegal halts per week, which are nearly always due to a lost interrupt on disk transfer and time lost is less than 30 seconds.

\section{CORRUPTED DATA}

Occasionally a record becomes corrupted; the exact reason for this is not known but it usually occurs on input when the system is very busy. There are two solutions. The operator may arrange for the result to be handwritten and then change the unit number of that patient to a dummy number so that no further requests will be added to the corrupted record. Alternatively, the record may be read down from disk at the close of the day, listed and repaired by the
Octal Debug program, and written back to its original location. This technique is sometimes employed for the longer cumulative reports.

\section{Discussion}

This report describes the implementation of an experiment in laboratory data handling financed by the Department of Health and Social Services. The principal aim of the experiment was to identify the advantages and limitations of a trace reader system within the laboratory. This objective enabled departmental staff to work directly together with the computer company in order to design a purposebuilt system for the King's College Hospital Group. Specially trained computer operators or programmers were not included in the initial operational concept and the system, like that of Abernethy, Bentley, Gartelmann, Gray, Owen, and Quan Sing (1970), was designed to be operated by laboratory staff with a minimum of training in computer techniques.

The initial approach of using a trace reader to input AutoAnalyzer I peak results into the computer enabled the main features of the system, such as peripheral printout of cumulative reports, to be developed before consideration of the difficult technical problems of full on-line working of Technicon SMA machines. However, the initial experiment was completed when the trace reader reached its work load capacity. This occurred in advance of the possibility of introducing on-line working, owing to the continuing rise in laboratory work of about $20 \%$ per annum, which has led to the present daily number of probes on the trace reader of about 5000 . However, work loads exceeding 2000 probes undoubtedly require on-line working.

The key to success of the system was the use of the disk as (1) a spooling device, (2) rapid access data store, (3) a program overlay store.

Spooling is a function which could have been performed in core, but would take up too much core store, when, for example, assembling a worksheet ready for printing out. When the spooling is diskbased, the job can be assembled in core, then written onto the disk spooling track, awaiting teletype time for output while another job is being processed by the CPU. The advantage of disk over magnetic tape for this purpose is that several jobs can be held and printed out simultaneously on different teletypes, because the access time is much faster than magnetic tape.

This disk has proved very efficient as a rapid access data store (1) for obtaining results quickly in response to telephone queries (not possible with magnetic tape); (2) for speeding up patient data 
input, which is one of the largest data handling problems in pathology laboratory systems.

Use of the disk as a program overlay store to supplement the $8 \mathrm{~K}$ core led to considerable improvement in the versatility and general usefulness of the system. The resulting availability of all software functions in real-time with rapid access (not possible with magnetic tapes) was one of the main reasons for the general acceptability of the system. However, this approach was responsible for the limited speed of the system; we would recommend that all major functions such as the patient input and report generator, should be core-based, while those used only occasionally, eg, statistics, housekeeping, should be disk based.

The major problems in designing a pathology laboratory system are (1) defining the job that the computer will do; (2) designing a system with all the flexibility of a non-computerized laboratory; (3) choice of computer. The second problem is the most difficult, and it is in this area that we have concentrated, and, we feel, have made considerable progress. Comparisons with magnetic-tape-based systems, such as the Elliott 903, show that while a disk-based system has the disadvantage of limitation of longterm storage of patients' records, this is outweighed by the speed of response enabling (1) worksheets to be printed on demand, so that analyses of specimens is not delayed by the computer; (2) patient's results to be printed on demand, which greatly reduces the time spent on telephone queries; (3) conversational mode of data input and interrogation. This facility has greatly reduced the time spent on patient data input, and will be considerably extended in the next phase of our system.

The lessons learned with the system are comparable with those provided by earlier British chemical pathology systems (Flynn, 1969), some of which have used more sophisticated equipment than was made available to us. Our major constraint in the selection of hardware was that of money. We would agree with Whitby and Simpson (1973) that some decisions were made too early and with too arbitrary a financial ceiling. We were also allowed to make the same serious error initially of not having laboratorybased program writing, but this was corrected in 1971. Again the 'expanded' 1971 system with $12 \mathrm{~K}$ core is less than the $16-32 \mathrm{~K}$ now recognized as the minimum compatible with programming efficiency (Whitby and Simpson, 1973). The major dependence of our system on system overlays on the disk allowed a certain measure of flexibility so that some in-house revision of the system was possible, but the need for 'clear and concise documentation' was again not fully appreciated and has led to delays in amending programs.

An important aspect of using computers in pathology laboratories is that they should be economic as assessed by cost-benefit analysis (Review for the National Health Service, 1971, Using Computers to Improve Health Services). The Department of Health and Social Security carried out studies in our laboratory as part of a costbenefit analysis by timing work operations, specimen analysis time, and report distribution time at various stages of the experiment. For various reasons this study was never completed.

The system established at King's College Hospital has certainly reduced clerical work and errors. The production of reports is faster, especially at the peripheral hospitals, due to the immediate teletype output. Like the Elliott A but not the B systems, we were able to produce limited computer-prepared cumulative reports. These make detection of gross errors much easier and the presentation of results is more compact and accessible to the clinician. The system has insufficient core for sophisticated? statistical routines but the daily mean and standard deviation are a great help in setting up Cusum charts and for quality control purposes.

\section{References}

Abernethy, M. H., Bentley, G. T., Gartelmann, D., Gray, P., Owen, J. A., and Quan Sing, G. D. (1970). An improved computerbased, multi-channel system for automatic chemical analysis. Clin. chim. Acta, 30, 463-482.

Flynn, F. V. (1969). Problems and benefits of using a computer for laboratory data processing. J. clin. Path., 22, Suppl. (Coll. Path.) 3, 62-73.

Gray, C. H., and Walter, M. (1971). The application of a computer system to automated clinical chemistry. Brit. J. hosp. Med. 6, Equipment Supplement, November, p. 25.

Hirst, A. D., and Howorth, P. J. N. (1974). Development and Evaluation of a 6 channel automated analyzer for $24 \mathrm{~h}$ urine specimens. Ann. clin. Biochem., in the press.

Review for the National Health Service (1971). Using Computers to Improve Health Services. Department of Health and Social Security, London.

Whitby, L. G., and Simpson, D. (1973). Routine operation of an Elliott 903 computer in a clinical chemistry laboratory. J. clin. Path., 26, 480-485. 